\title{
STILISTIKA DALAM PUISI "KERIKIL TAJAM DAN YANG TERAMPAS DAN YANG PUTUS” KARYA CHAIRIL ANWAR
}

\author{
Inayah Januarti \\ Jurusan Pendidikan Bahasa dan Sastra Indonesia \\ Fakultas Keguruan dan Ilmu Pendidikan
}

\begin{abstract}
Abstrak
Permasalahan yang dibahas dalam penelitian ini, yaitu: (1) Bagaimana bentuk asonansi dan aliterasi dalam kumpulan puisi Kerikil tajam dan yang terampas dan yang Putus karya Chairil Anwar? (2) Bagaimana pemilihan konotasi dan denotasi dalam diksi yang terdapat dalam kumpulan puisi Kerikil tajam dan yang terampas dan yang Putus karya Chairil Anwar? (3) Bagaimanakah makna gaya bahasa dalam kumpulan puisi Kerikil tajam dan yang terampas dan yang Putus karya Chairil Anwar.

Metode yang digunakan dalam penelitian ini adalah metode deskriptif kualitatif. Teknik pengumpulan data yang digunakan dalam penelitian ini adalah teknik catat, karena data-datanya berupa teks.

Berdasarkan analisis ini dapat disimpulkan beberapa hal, yaitu: (1) Pemanfaatan atau pemilihan bunyi-bunyi bahasa yang dipergunakan dalam Puisi Kerikil tajam dan yang Terampas dan yang Putus karya Chairil Anwar, ditemukan adanya asonansi 'persamaan bunyi vokal' yang banyak dipakai bunyi $a, i, u, e$, o. Aliterasi 'persamaan bunyi konsonan yang digunakan dalam Puisi Kerikil tajam dan yang Terampas dan yang Putus karya Chairil Anwar adalah bunyi konsonan /p/, /s/, /g/, /k/, /t/,/l/,/k/./m/ dan /b/. (2) Diksi dalam puisi Kerikil tajam dan yang Terampas dan yang Putus karya Chairil Anwar dapat ditinjau dari segi kosakata, pemilihan kata, dan denotasi serta konotasinya. (3) Pemakaian gaya bahasa yang terdapat dalam puisi Kerikil tajam dan yang Terampas dan yang Putus karya Chairil Anwar adalah (a) metafora, (b) alusio, (c) hiperbola, (d) sinestesia, (e) alegori, (f) personifikasi, (g) fabel (h) simbolik, (i) repetisi.
\end{abstract}

Kata kunci: Stilistika, diksi, gaya bahasa, aspek bunyi

\begin{abstract}
The problems discussed in this study, namely: (1) How do the assonance and alliteration in poetry collection sharp gravel and seized and that the End works Anwar? (2) How does the selection of connotation and denotation in diction contained in a collection of poems sharp gravel and seized and that the End works Anwar? (3) What is the meaning of the language in the style of a collection of poetry and sharp gravel seized and the work of Anwar Disconnect.

The method used in this research is descriptive qualitative method. Data collection techniques used in this research was noted, because the data in the form of text. Based on this analysis we can conclude several things, namely: (1) The use or selection of language sounds used in Poetry Gravel sharp and seized and that the End works Anwar, found their assonance 'equation vowel' a widely used sound $a, i, u, e$, o. Alliteration 'equation consonant sounds used in Poetry Gravel sharp and seized and that the End works Anwar is consonant / p /, / s /, $/ \mathrm{g} / \mathrm{l} / \mathrm{k} / \mathrm{l} / \mathrm{t} / \mathrm{l} / \mathrm{l} / \mathrm{/} / \mathrm{k} / \mathrm{lm} /$ and $/ \mathrm{b} / \mathrm{l}$ (2) Gravel sharp diction in poetry and seized and that the End Anwar's work can be viewed in terms of vocabulary, diction, and denotation and connotation. (3) Use a style that is contained in the poem Gravel sharp and seized and that the End works Anwar is (a) metaphor, (b) allusion, (c) hyperbole, $(d)$ synesthesia, $(e)$ the allegory, $(f)$ personification, $(g)$ fable $(h)$ the symbolic, $(i)$ reps.
\end{abstract}

Keywords: Stilistika, diction, style, sound aspects

\section{PENDAHULUAN}

Kajian stilistika merupakan bentuk kajian yang menggunakan pendekatan obyektif. Kajian stilistika digunakan untuk memudahkan menikmati, memahami, dan menghayati sistem tanda yang digunakan dalam karya sastra yang berfungsi untuk mengetahui ungkapan ekspresif yang ingin diungkapkan oleh pengarang Melalui kajian stilistika diharapkan dapat memperoleh hasil yang memenuhi kriteria obyektifitas dan keilmiahan (Aminuddin 1995:42).

Stilistika adalah suatu kajian yang digunakan untuk memudahkan menikmati, memahami, dan menghayati sistem tanda yang digunakan dalam karya sastra yang berfungsi untuk mengetahui ungkapan ekspresif yang ingin diungkapkan oleh pengarang. Pengkajian stilistika ini memperlihatkan adanya relevansi linguistik terhadap karya sastra. Melalui pendekatan stilistika dapat dijelaskan interaksi 
yang rumit antara bentuk dan makna yang sering luput dari perhatian dan pengamatan para kritikus sastra (Sudijman, 1993:vii). Sebab kajian stilistika dalam sastra melihat bagaimana unsur-unsur bahasa digunakan untuk melahirkan pesan-pesan dalam karya sastra. Dengan kata lain, kajian stilistika berhubungan dengan pengkajian pola-pola bahasa dan bagaimana bahasa digunakan dalam tes sastra secara khas.

Karya sastra pada analisis stilistika memiliki kaitan erat dengan bahasa yang menjadi medium utamanya. Ratna (2009:330) menyatakan bahwa analisis stilistika yang baik adalah kajian yang memelihara keseimbangan antara prinsip linguistik dan sastra kebudayaan.prinsip pertama, didasarkan atas kontras, perbedaan, persamaan, kesejajaran, pengulangan, mengerasakan, dan melemahkan arti, sedangkan prinsip kedua didasarkan atas pencapaian aspek estetis.

Dalam karya sastra, khususnya puisi bahasa merupakan sebuah media yang digunakan oleh pengarang dalam mengungkapkan perasaannya mengenai suatu hal. Sejalan dengan ini Pateda (2010:98) mengatakan bahwa penulis karya sastra pandai sekali memilih kata yang mengandung makna afektif sehingga pembaca terharu, jengkel, sedih, gembira, atau tertawa membaca karangan tersebut. Memang kita tidak akan sadar dengan apa yang akan kita rasakan setelah membaca sebuah karya sastra. Terkadang tanpa kita sadari, karya sastra yang kita baca mengajak kita untuk merasakan perasaan sedih, haru, kecewa, bahagia, dan perasaan lain sesuai dengan suasana apa yang ditimbulkan oleh pengarang.

Diksi merupakan unsur leksikal dalam gaya bahasa (Nurgiyantoro 2010:290). Diksi mengacu pada pengertian penggunaan katakata tertentu yang sengaja dipilih oleh pengarang. Mengingat karya sastra adalah dunia kata, komunikasi dilakukan dan ditafsirkan lewat kata-kata. Pemilihan kata-kata tersebut tentunya melewati pertimbanganpertimbangan tertentu untuk memperoleh efek ketepatan dan efek keindahan. Efek itu sendiri secara sederhana dapat dipertimbangkan dari segi bentuk dan makna untuk mendukung estetis karya sastra yang bersangkutan, mampu mengkomunikasikan makna, pesan, dan mampu mengungkapkan gagasan yang dimaksudkan oleh pengarang. Pemilihan kata dalam hal itu disebut dengan diksi.
Pengkajian pada puisi secara struktural menyangkut beberapa aspek diantaranya adalah tipografi, irama termasuk didalamnya metre dan rima, kata (diksi, denotasi dan konotasi, bahasa kias-majas, pencitraan). Keseluruhan aspek struktural ini pada dasarnya juga ingin mendukung tema yang diangkat oleh pengarang.

Gaya bahasa adalah bahasa indah yang digunakan untuk meningkatkan efek dengan jalan memperkenalkan serta membandingkan suatu benda atau hal tertentu dengan benda atau hal lain yang lebih umum (Tarigan 2009:4). Gaya bahasa merupakan bentuk retorik, yaitu penggunaan kata-kata dalam berbicara atau menulis untuk meyakinkan atau mempengaruhi penyimak dan pembaca.

\section{METODE PENELITIAN}

Sesuai dengan permasalahan yang diajukan yaitu fenomena kebahasaan yang terdapat dalam karya sastra, maka jenis penelitian ini adalah deskriptif kualitatif. Data yang bersifat deskriptif tersebut dianalisis untuk membuat generalisasi atau kesimpulan umum yang merupakan sistem atau kaidah yang bersifat mengatur atau gambaran dari objek penelitian (Subroto, 1992: 7).

Data dalam penelitian ini adalah data deskriptif yang berupa aspek bunyi, diksi, dan gaya bahasa dalam puisi Kerikil Tajam dan yang Terampas dan yang Putus karya Chairil Anwar. Adapun sumber data penelitian ini adalah Kerikil Tajam dan yang Terampas dan yang Putus.

Teknik pengumpulan data yang digunakan dalam penelitian ini adalah teknik catat, karena data-datanya berupa teks. Adapun langkahlangkah dalam pengumpulan data sebagai berikut: 1) membaca kumpulan puisi Kerikil Tajam dan yang Terampas dan yang Putus; 2) mencatat kalimat-kalimat yang menggunakan aspek bunyi, diksi, dan gaya bahasa.

Teknik deskriptif kualitatif digunakan untuk menguraikan permasalahan yang menjadi topik dalam penelitian ini sehingga diperoleh pembahasan yang lebih terperinci. Teknik kualitatif deskriptif ini bertujuan untuk mengungkap semua masalah yang telah diungkapkan dalam rumusan masalah yaitu penggunaan bunyi, diksi dan gaya bahasa dalam kumpulan puisi Kerikil Tajam dan yang Terampas dan yang Putus karya Chairil Anwar. Data 
yang telah terkumpul atau didokumentasikan kemudian dianalisis sehingga permasalahan yang menjadi topik dalam penelitian ini dapat terselesaikan.

\section{HASIL PENELITIAN DAN PEMBAHASAN}

\section{Aspek Bunyi Bahasa dalam Puisi Kerikil tajam dan yang Terampas dan yang Putus karya Chairil Anwar}

\section{a. Kerawang Bekasi}

Pada bait pertama puisi "Kerawang Bekasi" mengandung bunyi yang semacam/sama. Pada bait satu terdapat asonansi "a" dan "i" dan aliterasi "k-l". pada bait satu juga terdapat sajak awal, tengah, dan akhir yang sama yaitu "i". asonansi "a" dan "i" juga terlihat pada bait kedua. Begitu juga aliterasi pada bait kedua juga menggunakan huruf "k-1". Namun, sajak yang digunakan tidak senada. Hal itu dapat dilihat pada penggalan puisi berikut ini.

Tapí siapakah yang tịdak lagi mendengar deru kami,

Terbayang kami maju dan berdegap hati?

Bait lima dan bait enam memiliki asonansi bunyi "a" dan "I" yang diselingi dengan bunyi "u". Aliterasi dari kedua bait tersebut berbeda. Untuk bait kelima, memiliki aliterasi " $\mathrm{k}-\mathrm{m}$ " sedangkan pada bait keenam memiliki aliterasi " k-b". perbedaan aliterasi itu dimaksudkan agar bunyi yang dihasiklan berbeda dan bervariasi. Selain asonansi dan aliterasi, kedua bait tersebut memiliki persajakan yang hampir sama. Keduanya memiliki sajak awal "I" sajak tengah "I" dan sajak akhir" a". hal tiu terlihat dari kutipan di bawah ini.

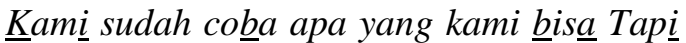

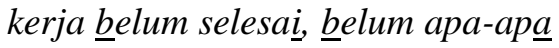

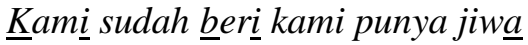
$\underline{K}$ erja $\underline{b}$ elum selesai, $\underline{b}$ elum $\underline{\text { bisa }}$ memperhitungkan arti 4-5 ribu nyawa

Kenang, kenanglah kami

Teruskan, teruskanlah jiwa kami Menjaga $\underline{B}$ ung $\underline{\text { Karno }}$ Menjag $\underline{a}$ $\underline{B}$ ung Hatta Menjaga Bung Syahrir

Pada dua bat terakhir, mengandung asonansi "a" diselingi "i-e-u". selain itu juga mempunyai aliterasi " $\mathrm{k}$ " yang diselingi " $\mathrm{m}-\mathrm{b}-\mathrm{t}$ ". persajakan yang digunakan pun dominan mengguanakan persajakan awal " e" sajak tengah " a" dan sajak akhir "i". persajakan yang bervariasi tersebut membuat puisi menjadi terkesan berwarna dan tidak monoton.

b. Aku

Pada puisi tersebut dapat ditemukan adanya persamaan bunyi u pada kata waktuku, kumau, merayu, dan itu. Persamaan bunyi vokal seperti itu disebut asonansi. Pada baris 6 dan 7 dapat dtemukan persamaan bunyi $n g$ pada kata binatang, jalang, dan terbuang. Persamaan bunyi konsonan seperti itu disebut aliterasi.

c. Kepada pemita-minta

Pada bait pertama baris pertama terdapat asonansi $a$ dan aliterasi $k$, dibaris kedua terdapat asonansi $a$ : menyerahkan, dan segala, dosa, begitu juga pada baris ketiga juga masih terdapat asonansi $a$ secara berturut turut: tapi, jangan, tentang, lagi, aku. Sedangkan pada bait kedua juga masih banyak terdapat asonansi $a$ dan $e$ pada baris ke tiga.

\section{d. Diponegoro \\ Sekali berarti \\ Sudah itu mati}

Bunyi I pada kata itu akan menghasilkan suara yang tinggi. Sehingga terdapat penekanan pada setiap kata. Selain bunyi I, ada juga bunyi u dan a

Maju

Ini barisan tak bergenderang-berpalu Kepercayaan tanda menyerbu

Bunyi u yang dihasikan pada kata-kata itu, akan menimbulkan suara atau bunyi yang bulat dan merdu. Selain itu, bunyi u cocok digunakan untuk bunyi panjang. Misalnya kata 'maju' bisa dibaca 'majuuuuuuuu' (panjang). Sebagai kombinasi bunyi, pengarang juga memunculkan bunyi lemah pada puisinya. Misalnya bunyi a. Bunyi a ini akan menjadi pereda bunyi-bunyi tinggi yang telah mendominasi, sehingga suasana tidak selalu tegang.

\section{e. Derai-derai Cemara}

Dalam bait ini terdapat asonasi a dan i, karena pada umumnya dalam sajak itu bunyibunyi yang dominan adalah vokal suara a,i dan , $\mathrm{u}$ dan bunyi sengau: $\mathrm{m}, \mathrm{n}, \mathrm{ng}$. seperti pada 
bait tersebut yang difungsikan oleh penyair untuk menyatakan ketidakmampuan dia menghadapi kenyataan yang akan datang. Cemara menderai sampai jauh Terasa hari akan jadi malam. Ada beberapa dahan di tingkap merapuh Dipukul angin yang terpendam

Diksi dalam Puisi Kerikil tajam dan yang Terampas dan yang Putus karya Chairil Anwar

\section{a. Kerawang Bekasi}

Pilihan kata yang digunakan oleh Sang Penyair pada karya "Karawang-Bekasi" yang terdapat pada kalimat "Kami yang terbaring antara Karawang-Bekasi, tidak bisa teriak "Merdeka" dan angkat senjata lagi". Pada kata "terbaring" mempunyai makna denotasi tidur terlentang, tetapi Sang Penyair menggunakan kata "Terbaring" yang mempunyai makna konotasi meninggal dunia, atau kematian.

"kenang, kenanglah kami, kami sudah coba apa yang kami bisa memperhitungkan 4-5 ribu nyawa". Pada kalimat tersebut terdapat makna denotasi yang bermakna perjuangan itu penuh resiko tetapi penyair mengatakan ia sudah mencoba apa yang ia bisa walaupun nyawa taruhannya. Meski begitu apa yang dilakukan belum selesai, perjuangan itu akan terus berlanjut sampai hayat dikandung badan.

\section{b. Aku}

"kalau sampai waktuku"

Pemilihan kata pada kata "kalau sampai waktuku" yang bermakna konotasi berarti penyair mengungkapkan bahwa kalau hari ajalnya tiba atau arti lainnya jikalau aku ini mati.

"Ku mau tak seorang 'kan merayu"

Dari bait ini bermakna denotasi karena dapat dianalisis bahwa pemilihan kata si penyair sangat tepat, karena kata "Ku mau tak seorang 'kan merayu" Merupakan pengganti dari kata "ku tahu". Penyair tahu bahwa tidak ada satu orangpun yang bisa merayu.

c. Kepada peminta-minta

Baik, baik, aku akan menghadap

dia Menyerahkan diri dan segala

dosa Tapi jangan lagi tentang

aku Nanty darahku jadi beku.

Pada bait tersebut mengandung makna konotasi karena sumu itu menunjukkan bahwa orang yang sadar kepada dosa-dosanya iru rasanya sangat sakit dan sangat menderita, rasa dosa yang begutu hebat sehingga mengganggu sampai ke mimpi. Si aku berjanji akan selalu akan mengingat Tuhan dan menyerahkan dirinya, ia sudah sadar dan merasa betul-betul bersalah, maka ia sangat tersiksa bila ditentang lagi atau diperingatkana akan dosa-dosanya membuat ia mati ketakutan karena dosa tersebut

Sudah tercacar semua dimuka Nanah

\section{meleleh dari muka}

Pada bait tersebut mengandung makna konotasi. Seperti kata cacar dan bernanah, selalu meleleh, dan selalu diusap oleh sipeminta-minta sambil berjalan. Seolah-olah si peminta-minta itu selalu mengingatkan rasa dosa si aku di mana pun ia berada.

Mengganggu dalam mimpiku

Menghempas aku di bumi keras

Pada bait tersabut mengandung makna denotasi karena rasa dosa iu

begutu hebatnya sehingga menggganggunya sampai kemimpi si aku. Rasanya si aku seperti dihempaskan di bumi yang keras oleh rasa dosa yang selalu mencekeramnya, selalu mengejarngejarnya.

\section{d. Diponegoro}

Pada kata pembangunan di baris pertama yang bermakna denotasi bukan berarti pembangunan secara fisik seperti membangun gedung atau tempat lain. Tetapi, kata pembangunan dalam puisi ini mempunyai makna untuk membangun semangat meraih kemerdekaan.

Kata dan bara kagum menjadi api yang bermakna konotasi pada bait kedua baris ketiga bukan mempunyai arti api pada umumnya yang berupa cahaya dari sesuatu yang terbakar. Tetapi kata api pada puisi ini mempunyai makna kekaguman Chairil Anwar kepada Diponegoro.

Pada bait kesebelas memang setiap kata bunyi berbeda, kata Maju yang bermakna denotasi pada baris keduapuluh sebenarnya mempunyai makna berjalan ke muka atau kedepan. Kata Serbu pada baris keduapuluh satu mempunyai makna mendatangi dengan maksud melawan. Kata Serang yang bermakna denotasi pada baris keduapuluh dua juga mempunyai makna mendatangi untuk melawan. Kata Terjang bermakna denotasi pada baris keduapuluh tiga juga mempunyai makna yang sebenarnya hampir sama dengan serang. Pada bait kesebelas ini mempunyai makna bersama yaitu untuk melawan penjajah. 
e. Derai-derai Cemara

Pada bait pertama diawal kalimat yang bermakna denotasi menceritakan tentang cemara, cemara yang merupakan suau jenis pepohonan dengan daun yang kecil da meruncing.

Pada bait kedua yang bermakna konotasi, tokoh puisi merupakan sosok yang telah meninggalkan masa lalunya, masa kanakkanaknya dan telah meninggalkan masa lalunya dan telah menunjukkan kedewasaan.

Bait kedua dan ketiga Kata 'terasing' mengandung rasa keterasingan. Sedangkan kata 'jauh' menunjukkan jarak yaitu angan-angan masa kanak-kanak yang cemerlang penuh harapan di masa yang akan datang, tetapi kenyataannya hidup ini penuh penderitaan. Sehingga kata jauh lebih tepat daripada kata terasing.

Isi dalam puisi ini, sangat patut kita renungkan sebagai nasihat dan pepatah hidup kita. Seperti, kata-kata hidup hanya menunda kekalahan telah menjadi semacam pepatah dan terasa tidak asing di telinga kita. Kiasan kekalahan sangat menarik untuk diperhitakan; padahal yang kita kenal selama ini adalah hidup hanya menunda kemenangan. Kekalahan adalah simbol dari kepasrahan dan sangat kental dengan aroma kematian.

\section{Pemakaian Gaya Bahasa dalam Puisi Kerikil tajam dan yang Terampas dan yang Putus karya Chairil Anwar}

\section{a. Kerawang Bekasi}

Metafora adalah gaya bahasa yang membuat suatu benda tidak mempunyai sifatnya yang biasa, melainkan sifat yang lain. Hal ini terlihat pada kutipan puisinya yaitu "aku sekarang api aku sekarang laut", disini sang penyair mengibaratkan dirinya seperti laut dan api. Karena api cendrung mempunyai hawa yang panas yang bias membakar sesuatu, sedangkan mempunyai sifat seperti laut karena laut selalu bergelombang dikala ada ombak datang menghadang dan kadang kala bisa tenang sehingga menimbulkan kedamaian jika kita memandangnya.

Personifikasi adalah gaya bahasa yang membuat suatu benda mati bertingkah seperti manusia. Pada puisi "Krawang Bekasi" hal ini tampak pada kutipan puisinya yaitu "kami sekarang mayat, berikan kami arti". Pada puisi ini tersirat makna seakan-akan mayat yang secara sifat tidak dapat berbicara bahkan bergerak, tetapi oleh pengarang "mayat" tersebut dibuat seolah-olah dapat berbicara seperti manusia hidup.

\section{b. Aku}

Pada bait puisi "Aku ini binatang jalang", menunjukan bahwa terdapat gaya bahasa simbolik yang melukiskan sesuatu dengan menggunakan simbol atau lambang untuk menyatakan maksud. Dalam kalimat ini menyatakan dengan jelas bahwa penulislah yang seolah-olah menjadi ukuraan masyarakat pada masanya. Namun, apabila bait tersebut digabungkan dengan bait selanjutnya " Dari kumpulannya terbuang ", maka dapat disimpulkan bahwa terdapat majas fable. Yang menyatakan perilaku binatang sebagai manusia yang dapat berpikir dan bertutur kata.

Tak perlu sedu sedan itu " dalam bait puisi tersebut, dikatakan bahwa unsur majas yang terkandung di dalamnya adalah majas hiperbola. Yang mana hiperbola itu suatu majas yang bisa disebut juga sebagai ungkapan pengeras. Bahasa ini menggantikan kata sederhana menjadi luar biasa kedengarannya.

Penjabaran majas selanjutnya terdapat pada kalimat " Hingga hilang pedih perih ". Majas yang terkandung dalam bait puisi tersebut adalah majas simbolik. Dengan membandingkan benda yang sesungguhnya dengan benda lain sebagai lambang sifatnya sebagai maksud. Kata " Pedih " yang berarti melambangkan mata sebagai tujuan maksud dari bait tersebut, dan kata " Perih " yang berarti melambangkan indra peraba. Perih dilambangkan sebagai lambang perasaan seseorang ketika menggunakan indra perabanya.

\section{c. Kepada Peminta-minta}

Dalam puisi Kepada Peminta-minta karya Chairil Anwar terdapat bahasa figuratif yang muncul yaitu pada baris ke 4 dan 20 . Merupakan majas hiperbola yang bersifat berlebih-lebihan. Muncul majas hiperbola dari kata nanti darahku jadi beku. Selain itu pula muncul majas repetisi pada baris 1 dan 18 . Terjadi pengulangan pada kata baik, dalam konteksnya yaitu baik, baik aku akan menghadap Dia.

d. Diponegoro

Dalam puisi Diponegoro saya menemukan majas perbandingan, hiperbola yaitu pada "Ini barisan tak bergenderang- 
berpalu". Kalimat tersebut dikategorikan sebagai majas hiperbola karena melebihlebihkan barisan yang bergenderan-berpalu.

\section{e. Derai-derai Cemara}

Pada bait puisi "Cemara menderai sampai jauh", menunjukan bahwa terdapat gaya bahasa simbolik yang melukiskan sesuatu dengan menggunakan simbol atau lambang untuk menyatakan maksud. Dalam kalimat ini menyatakan jelas bahwa penulislah yang mengalami gejolak batik pada dirinya.

Namun, apabila bait tersebut digabungkan dengan bait selanjutnya "terasa hari akan jadi malam", maka dapat disimpulkan bahwa terdapat majas satire yang merupakan gaya bahasa sejenis ironi yang mengandung kritik atas kelemahan manusia agar terjadi kebaikan dan tidak jarang satire muncul dalam bentuk puisi yang mengandung kegetiran tapi ada kesadaran untuk berbenah diri.

\section{KESIMPULAN DAN SARAN}

\section{Kesimpulan}

Berdasarkan hasil analisis kajian stilistika puisi Kerikil tajam dan yang Terampas dan yang Putus karya Chairil Anwar yang telah dilakukan, dapat disimpulkan sebagai berikut.

a. Pemanfaatan atau pemilihan bunyi-bunyi bahasa yang dipergunakan dalam Puisi Kerikil tajam dan yang Terampas dan yang Putus karya Chairil Anwar, ditemukan adanya asonansi 'persamaan bunyi vokal' yang banyak dipakai bunyi $a, i, u, e, o$. Aliterasi 'persamaan bunyi konsonan yang digunakan dalam Puisi Kerikil tajam dan yang Terampas dan yang Putus karya Chairil Anwar adalah bunyi konsonan $/ \mathrm{p} /$, $/ \mathrm{s} /, / \mathrm{g} /, / \mathrm{k} /, / \mathrm{t} /, / \mathrm{l} / / \mathrm{l} / . / \mathrm{m} /$ dan $/ \mathrm{b} /$.

b. Diksi dalam puisi Kerikil tajam dan yang Terampas dan yang Putus karya Chairil Anwar dapat ditinjau dari segi kosakata, pemilihan kata, dan denotasi serta konotasinya.

c. Pemakaian gaya bahasa yang terdapat dalam puisi Kerikil tajam dan yang Terampas dan yang Putus karya Chairil Anwar adalah (1) metafora, (2) alusio, (3) hiperbola, (4) sinestesia, (5) alegori, (6) personifikasi, (7) fable (8) simbolik, (9) repetisi.

\section{Saran}

Dari penelitian terhadap kumpulan puisi Kerikil tajam dan yang Terampas dan yang
Putus karya Chairil Anwar penulis memberi saran kepada pembaca sebagai berikut:

a. Hasil penelitian stilistika diharapkan dapat menambah khazanah penelitian sastra dan dapat menjadi referensi penelitian sastra berikutnya yang menggunakan pendekatan stilistika dengan memfokuskan teori diksi dan majas.

b. Kumpulan puisi yang dipergunakan sebagai media penelitian ini diharapkan dapat dianalisis dengan pendekatan lain, seperti struktural dan semiotik.

\section{DAFTAR PUSTAKA}

Aminuddin. 1995. Stilistika Pengantar Memahami Bahasa Dalam Karya Sastra. Semarang: IKIP Semarang Press.

Nurgiyantoro, Burhan. 2010 (Cet. ke-8). Teori Pengkajian Fiksi. Yogyakarta: Gajah Mada University Press.

Ratna, Nyoman Kutha. 2009. Stilistika, Kajian Puitika Bahasa dan Budaya Yogyakarta: Pustaka Pelajar.

Pateda, M. 2010. Semantik Leksikal. Jakarta: Rineka Cipta

Subroto, Edi D., dkk. 1992. Tata Bahasa Deskriptif Bahasa Jawa. Jakarta: Departemen Pendidikan dan Kebudayaan.

Sudjiman, Panuti. 1993. Bunga Rampai Stilistik. Jakarta: Pustaka Utama Grafiti.

Tarigan, Henry Guntur. 2009. Pengajaran Gaya Bahasa. Bandung: Angkasa. 